\title{
An evaluation of pediatric cases with trigger finger
}

\author{
Alper Çıraklıa ${ }^{\text {* }}$, Ahmet Pişkin ${ }^{\mathrm{a}}$, Murat Erdoğana ${ }^{\mathrm{a}}$, Sevgi Çıraklı ${ }^{\mathrm{b}}$, Hicabi Sezgin ${ }^{\mathrm{a}}$ \\ ${ }^{a}$ Department of Orthopedics and Traumatology, Faculty of Medicine, Ondokuz Mayls University, Samsun, Turkey \\ ${ }^{b}$ Department of Pediatrics, Faculty of Medicine, Ondokuz Mayıs University, Samsun, Turkey
}

\section{ARTICLE INFO}

\section{Article History}

$\begin{array}{ll}\text { Received } & 18 / 05 / 2013 \\ \text { Accepted } & 23 / 05 / 2013\end{array}$

\section{* Correspondence to:}

Alper Çıraklı

Department of Orthopedics and Traumatology, Faculty of Medicine, Ondokuz Mayıs University,

Samsun, Turkey

e-mail: alperomu@gmail.com

\section{ABSTRACT}

Trigger finger is a rarely seen condition in childhood. It generally occurs in the thumbs and in the differential diagnosis flexion deformities originating in the joint should be included. This study comprised 23 cases in 19 children who underwent surgery for trigger finger between 2005 and 2013 in our clinic. All the patients passed through the postoperative period without any problems. Several treatment methods are in use, however it is suggested that surgery is required as the first treatment option especially in childhood. Surgical treatment is made in the form of a percutaneous or open incision in the longitudinal plane of the A1 pulley system. In recent years, although percutaneous methods are in common use, open surgical methods have been thought to be more reliable as the surgical area is small and the digital veins and nerves can be easily damaged in pediatric cases. In addition, it can be considered necessary for early movement in the postoperative period.

\section{J. Exp.Clin. Med., 2013; 30: 225-227}

*It was accepted as a poster in National Congress of Orthopedics 2013. Antalya, Turkey.

\section{Keywords:}

Loosening

Pediatric

Surgical treatment

Trigger finger

\section{Introduction}

Trigger finger is the result of tendons entrapped in the A1 pulley due to thickening of the finger flexor tendons or nodule formation (Chambers, 2009). Trigger finger is most often seen in the $5^{\text {th }}$ and $6^{\text {th }}$ decade (Kelle, 2012). It is seen extremely rare in childhood (Pargali and Habibzadeh, 2011). It is generally seen in the thumbs and the pathology may be encountered as congenital or developmental (Kelle, 2012). Treatment choices include the use of splint/plaster, corticosteroid injections, physical therapy and percutaneous or open surgical loosening (Patel and Bassini, 1992).

This study aimed to evaluate the advantages of open surgery for trigger finger in pediatric cases with reports in literature.

\section{Method}

The study comprised 23 fingers of 19 children who underwent surgery for trigger finger between 2005 and 2013 in our clinic. Informed consent was obtained from all the families then the patient data were retrospectively evaluated from the hospital records and computer system. For the statistical analysis, SPSS 15.0 (SPSS Inc., Chicago, IL, USA) software program was used.

Surgery was performed under general anaesthesia and tourniquet. Generally a transverse incision was used and on some cases a T-shaped incision. Passing through the skin and subcutaneous tissue, the A1 pulley was reached and the loosening procedure was performed. In all patients, finger movements were made easily after the loosening procedure and no entrapment was observed. The surgery was finished with primary sutures of the skin. All the patients were encouraged to start finger movements in the early postoperative period. No intraoperative or postoperative complications were seen in any patient.

\section{Results}

Involvement of the thumb was observed in all cases. The cases were thirteen $(68.5 \%)$ males and six (31.5\%) females with a mean age of 29.4 months (range: 11-65 months); right hand involved in six $(47.3 \%)$, left hand in nine $(31.5 \%)$ and bilateral in four $(21 \%)$ of cases (Table 1). 


\begin{tabular}{cccc}
\multicolumn{2}{c}{ Table 1. Summary of cases } & & \\
Number & Age (Month) & Gender & Side of operation \\
\hline $\mathbf{1}$ & 15 & Boy & Left \\
$\mathbf{2}$ & 11 & Boy & Bilateral \\
$\mathbf{3}$ & 25 & Girl & Left \\
$\mathbf{4}$ & 20 & Boy & Left \\
$\mathbf{5}$ & 43 & Girl & Left \\
$\mathbf{6}$ & 39 & Boy & Right \\
$\mathbf{7}$ & 27 & Boy & Left \\
$\mathbf{8}$ & 60 & Girl & Right \\
$\mathbf{9}$ & 13 & Boy & Bilateral \\
$\mathbf{1 0}$ & 18 & Girl & Bilateral \\
$\mathbf{1 1}$ & 17 & Boy & Left \\
$\mathbf{1 2}$ & 39 & Boy & Left \\
$\mathbf{1 3}$ & 65 & Girl & Left \\
$\mathbf{1 4}$ & 31 & Boy & Bilateral \\
$\mathbf{1 5}$ & 24 & Boy & Right \\
$\mathbf{1 6}$ & 58 & Boy & Left \\
$\mathbf{1 7}$ & 27 & Girl & Right \\
$\mathbf{1 8}$ & 17 & Boy & Right \\
$\mathbf{1 9}$ & 59 & Boy & Right \\
\hline & & & \\
& 59 & & \\
\hline
\end{tabular}

The bilateral involvement occurred in three cases at the same time and in one case at an interval of 18 months. The mean time from onset of symptoms to surgery was determined as 8.5 months (range: 1-49 months). Within this time, no case had received any treatment other than surgery. The patient histories revealed no additional diseases or positive family history.

\section{Discussion}

In adults, trigger finger is most often seen in the $5^{\text {th }}$ and $6^{\text {th }}$ decade (Kelle, 2012). It is seen extremely rare in childhood (Pargali and Habibzadeh, 2011). The incidence in children is estimated to be between $0.05 \%$ and $0.3 \%$ (Ger et al., 1991). Trigger finger is generally seen in the thumbs in children and this has been reported to be 10 times more frequent than other triggering diseases of the fingers (Medina et al., 2008). This pathology may be encountered as either congenital or developmental (Kelle, 2012). Congenital trigger finger is dealt with under the heading of differentiation of hand anomalies together with arthrogriposis, camptodactyly, madelung deformity and clinodactyly (Ty and James, 2009). In addition, there may be accompanying cardiac, cleft lip and cleft palate pathologies. Although there are cases of congenital pathologies of trigger finger cases occuring later in life, there is no information related to symptoms in later life (Yenidünya, 2010). In the current study, all the cases were developmental pathology with thumb involvement.

The problem in trigger finger is that impairment in the viscosity of the finger flexor system inhibits movement. Generally the problem is located in the metacarpophalangeal joint anteriorly and results in the narrowing of the hard fibrous band of the A1 pulley. In the current study, the problem was in the A1 pulley in all the cases.

In the diagnosis, the families stated that the child's fingers were bent and they tried to correct pathology, however they were not successful or managed it with diffuculty and the child cried at that time. The importance for the differential diagnosis was to determine whether or not the flexion deformity originated in the joint. This is understood by the patient showing straightening of the interphalangeal joint when flexion is made from the metacarpophalangeal joint (Yenidünya and Tasbas, 1999).

Non-treatment of trigger finger causes flexion contracture in the interphalangeal joint (Wolfe, 2005). In this respect there is another significance. Some studies have reported spontaneous correction of the deformity, although those cases were below 12 months of age and were cases with mild symptoms (Ger et al., 1991; Moon et al., 2001). In the current study, the youngest case was 11 months old and because families were generally worried about surgical intervention, the children were brought to hospital at a mean 8.5 months after the onset of symptoms and during that time no improvement was reported. In contrast, Baek and Lee (2011) reported spontaneous recovery within four years of the great majority of cases followed-up without treatment. Treatment choices include the use of splint/plaster, corticosteroid injections, physical therapy and percutaneous or open surgical loosening (Patel and Bassini, 1992).

The use of a splint may be useful in early stage cases and adults (Colbourn et al., 2008). Problems of conformity in pediatric patients may result in failure of the treatment. However, in a study where long-arm plaster was applied to three patients aged 20,26 and 32 months, it was reported that symptoms had recovered (Saeed and Baghianimoghadam, 2012).

Although there are studies defining the application of corticosteroid injections as the right approach, it is not as foolproof as indicated. The close proximity of digital blood vessels and surface course may cause partial tissue necrosis as a result of an injection within the digital artery (Park and Dumanian, 2009).

Physical therapy methods include hot pack application, transcutaneous electrical nerve stimulation (TENS), ultrasound, friction massage and stretching exercises. Anti-inflammatory therapy may be given in addition to prevent inflammation. In two different studies where two cases aged four and five years old received physical therapy and anti-inflammatory therapy, positive results were reported from the treatment (Pargali and Habibzadeh, 2011; Kelle, 2012). In another study, the mothers of children with trigger thumb were taught passive stretching exercises and after a mean 28 months of application positive results were obtained in the vast majority of cases (Watanabe, 2001).

Although there are different treatment methods in use, it has been suggested that particularly in childhood, surgery is required as the first treatment (Sevencan et al., 2010). Surgical treatment is made in the form of a percutaneous or open incision in the longitudinal plane of the A1 pulley system. Amradi and Dardane (2011) reported very good results from loosening operations performed on 63 cases aged between 12 and 60 months.

Researchers have attempted the percutaneous approach, which has come into widespread use in recent years, because it consists of the loosening of the A1 pulley in the treatment of trigger finger. The percutaneous approach has been presented in literature as an alternative method with emphasis on surgery duration being longer than that of the open technique 
(Patel and Bassini, 1992). The advantages are that the incision is smaller and thus there is less pain and it allows for early movement. The disadvantages are that the surgical area is small and the digital blood vessels, nerves and flexor tendons are in close proximity. For example, in cadaver studies small longitudinal tears were determined in the flexor tendons with the percutaneous method (Bain et al., 1995). In this respect, the risk of damage to blood vessels, nerves and tendons is greater than in the open technique. Particularly in pediatric cases, the close proximity of these structures and their surface course, increases the risk.

In a study by Pope and Wolfe (1995) it was reported that percutaneous loosening was possible without cutting in the distal 10-15\% part of the pulley. Cebesoy et al, (2007) reported that after starting with the percutaneous method, after four weeks an open approach was applied to 4 of 25 fingers due to failure. In some studies, due to the thumb and first finger nerve tissue proximity, percutaneous loosening is recommended in the treatment of trigger finger (Bain et al, 1995; Wolfe, 2005 ). Nonetheless, the incision used in open surgery is $2 \mathrm{~cm}$ in length at the most. In addition, the incision is in a fortunate localisation in respect of scarring in the postoperative period. In the current study, as all the cases had involvement of the thumb and because of the risks, loosening with open surgery technique was applied. Other than these two methods, Ertürk et al. (2009) used a mini-open technique with an incision of $1 \mathrm{~cm}$ and reported that neurovascular structures could be easily visualised as in the open technique and no complications were encountered.

\section{Conclusion}

Trigger finger is a pathology rarely seen in children but which causes problems to develop if left untreated. Although different methods are used in treatment, surgical methods are preferred particularly for pediatric cases. Surgical loosening can be performed with percutaneous or open methods. In recent years, although percutaneous methods are in common use, open surgical methods have been thought to be more reliable as the surgical area is small and the digital veins and nerves can be easily damaged in pediatric cases. In addition, it can be considered necessary for early movement in the postoperative period.

\section{REFERENCES}

Amradi, A., Dardane, M.A., 2011. Percutaneous release of trigger thumb in children: 63 cases. Chir. Main. 30, $102-104$.

Baek, G.H., Lee, H.J., 2011. The natural history of pediatric trigger thumb: A study with a minimum of 5 years follow-up. Clin. Orthop. Surg. $3,157-160$.

Bain, G.I., Turnbull, J., Charles, M.N., Roth, J.H., Richards, R.S., 1995. Percutaneous A1 pulley release: A cadaveric study. J. Hand. Surg. Am. 20, 781-784.

Cebesoy, O., Köse, K.C., Baltaci, E.T., Isik, M., 2007. Percutaneous release of the trigger thumb: Is it safe, cheap and effective? Int. Orthop. 31, 345-349.

Chambers, R.G., 2009. Corticosteroid injection for trigger finger. Am. Fam. Physician. 80, 454.

Colbourn, J., Heath, N., Manary, S., Pacifico, D., 2008. Effectiveness of splinting for the treatment of trigger finger. J. Hand. Ther Am. 21, 336343.

Ertürk, C., Altay, M.A., Kalender, A.M., 2009. Mini-açık tetik parmak gevşetmesi. Tıp Araştırmaları Dergisi. 7, 141-144.

Ger, E., Kupcha, P., Ger, D., 1991. The management of trigger thumb in children. J. Hand. Surg. Am. 16, 944-947.

Kelle, B., 2012. Trigger finger in childhood: A case report. J. P.M.R. Sci. 15, 61-63.

Medina, J., Lorea, P., Marcos, A., Martin, F., Reboso, L., Foucher, G., 2008. Flexion deformities of the thumb: Clasped thumb and trigger thumb. Chir Main. 27, 35-39.

Moon, W.N., Suh, S.W., Kim, I.C., 2001. Trigger digits in children. J. Hand. Surg. Brith. 26, 11-12.

Pargali, N., Habibzadeh, F., 2011. Bilateral trigger finger in a 5-year-old child: Case report. J. Plast. Reconstr. Aesthet. Surg. 64, $283-284$.

Park, J., Dumanian, G.A., 2009. Shower emboli and digital necrosis after a single corticosteroid injection for trigger thumb: Case report. J. Hand. Surg. Am. 34, 313-316.

Patel, M.R., Bassini, L., 1992. Trigger fingers and thumb: When to splint, inject or operate. J. Hand. Surg. Am. 17, 110-113.

Pope, D.F., Wolfe, S.W., 1995. Safety and efficacy of percutaneous trigger finger release. J. Hand. Surg. Am. 20, 280-283.

Saeed Banadaky, S.H., Baghianimoghadam, B., 2012. Long arm casting for treatment of trigger finger in children: Report of three cases. J. Med. Life. 5, 105-106.

Sevencan, A., Inan, U., Kose, N., Omeroglu, H., Seber, S., 2010. Percutaneous release for trigger thumbs in children: Improvements of the technique and results of 31 thumbs. J. Pediatr. Orthop. 30, 705-709.

Ty, J.M., James, M.A., 2009. Failure of differentiation: Part II. Hand. Clin. 25, 195-213.

Watanabe, H., Hamada, Y., Toshima, T., Nagasawa, K., 2001. Conservative treatment for trigger thumb in children. Arch. Orthop. Trauma Surg. 121, 388-390.

Wolfe, S.W., 2005. Tenosynovitis. In: Green, D.P., Hotchkiss, R.N., Pederson, W.C., Wolfe, S.W., Green's operative hand surgery. Vol. 2 , $5^{\text {th }}$ ed. Philadelphia: Elsevier Churchill Livingstone, pp. 2137-2158.

Yenidünya, M.O., 2010. Tetik Başparmak: Doğumsal, gelişimsel ve geç bir sağllk sorunu olarak. Yeni Tıp Dergisi. 27, 33-36.

Yenidünya, M.O., Tasbas B.A., 1999. A simple sign for the differential diagnosis of the congenital trigger thumb. Plast. Reconstr. Surg. 103, 748-749. 